\title{
Concerns and mental health of teachers from digitally underdeveloped countries regarding the reopening of schools after the first wave of the COVID-19 pandemic
}

\author{
Sanja Milića,* and Nada Marićc, ${ }^{\mathrm{b}}$ \\ ${ }^{a}$ Faculty of Education, University of East Sarajevo, Republic of Srpska, Bosnia and Herzegovina \\ ${ }^{\mathrm{b}}$ Institute of Occupational Health and Sports Medicine of the Republic of Srpska-Center Bijeljina, Republic of \\ Srpska, Bosnia and Herzegovina
}

Received 2 June 2021

Accepted 28 July 2021

\begin{abstract}
.
BACKGROUND: Torn between the decision to return to school classrooms or continue holding online classes during COVID-19, teachers around the world feel great uncertainty.

OBJECTIVE: Bearing in mind that the study of mental health during the pandemic is of great importance for vulnerable categories, and given the role of teachers in society, the aim of this research is to assess teachers' concerns and anxiety before the start of the school year, and also to examine the factors related to them and propose measures in line with the results.

METHODS: The study was conducted as a cross-sectional study before the start of the 2020/2021 school year. The research sample consisted of 286 teachers. For the purposes of this research, a special questionnaire was constructed consisting of a general questionnaire and a Generalized Anxiety Disorder 7-item scale (GAD-7).

RESULTS: The strongest predictor of a teacher's answer that they were concerned about the reopening of schools was their concern for their own life and health and for the life and health of their family members, followed by the amount of information received about COVID-19, and, finally, older age. Only $2 \%$ of teachers had mild anxiety.

CONCLUSIONS: This research indicated that it is necessary to examine in more detail the degree of teachers' concern and its impact on their functionality and work process. It is also necessary to repeat the research on the mental health status of teachers and implement procedures in the form of a regular screening program of the mental health status of teachers or implement procedures of support in concern management.
\end{abstract}

Keywords: COVID-19, teachers, mental health, concerns, anxiety

\section{Introduction}

The situation caused by the COVID-19 pandemic is unique in the history of the world so far in terms of both the manner and speed of its occurrence, as

\footnotetext{
${ }^{1}$ ORCID ID 0000-0001-7750-0781.

*Address for correspondence: Dr. Sanja Milić, Faculty of Education, University of East Sarajevo, Republic of Srpska, Bosnia and Herzegovina. E-mail: sanja.milic@pfb.ues.rs.ba; ORCID ID 0000-0001-6182-4917
}

well as in terms of its global scope and consequences. The outbreak of the virus has dramatically impacted people's everyday lives, their family lives, political situations, and safety [1]. The pandemic has created a new crisis of human development by hitting all its constituent elements: the economy, health, education. In a situation that poses an obstacle and effects a significant change that interferes with normal work and causes another phenomenon as its consequence [2], the question of providing a minimum 
for the functioning of society and its institutions arises. What is certain is that the pandemic has had disproportionately greater consequences for unstable and underdeveloped countries [3], in all other areas of social policy and economics as well as in education $[4,5]$.

In situations of crises, no social institution, including the school, is spared from destruction. One of the priorities is to secure the teaching process in educational institutions with strict and mandatory protection of students, teachers and staff. The basic role of educational institutions is to ensure stability because both students and staff experience difficult situations outside the teaching context [6]. In times of social crises, educational institutions must achieve the planned goals and outcomes at least to a minimal extent. Teachers are required to model the teaching process and act beyond their traditional understandings of the overall teaching process organization, causing the emergence of a range of problems primarily related to curriculum transformation and training in the use of IT technologies [7]. Torn between the decision to return to school classrooms or continue holding online classes, teachers around the world feel great uncertainty. The former endangers health and life and the latter violates the autonomy of teachers. In addition to health concerns about returning to classrooms, teachers are also concerned that coronavirus safety measures will interfere with teaching and learning [8]. Teachers feel that they are not responsible for key questions about how schools will implement sanitary and epidemiological measures and how they will ensure physical and social distancing among students and prevent the further spread of the virus. A national survey of the second largest teachers' union, the American Federation of Teachers, shows that 3 out of 4 teachers said they were comfortable returning to school if certain precautions were met [9]. In this pandemic context, people with jobs that put them in physical contact with others are at the greatest risk of contracting COVID-19 [10].

Although there are currently many observational studies from several countries, such as models or meta-analyses that allow determining the low level of virus transmission in children compared to adults [11], age differences in infectivity have not been fully investigated [12]. Findings from several studies investigating contact among the infected suggest that children may be less contagious than adults [13], but the strength of this evidence is weak and some of the relevant studies were conducted when schools were closed [12]. It was also difficult for researchers to initially study virus transmission in children, as most schools switched to online learning when many states launched locking measures [14]. Furthermore, teachers' concerns are also caused by switching to online learning because it means that many teachers spend much more energy figuring out how to work with new technologies and adapt their curriculum, instead of focusing on the content they teach [14]. Another issue in a series of problems is that teachers had to prepare for both scenarios before the start of the school year. The fact that younger school-age children cannot reliably maintain physical distance and that teachers cannot apply distance and teach at the same time, and the fact that classes that require students to sit in one place, look straight ahead, and work independently violate good evidence-based teaching practices [12] further strengthen teachers' concern about reopening schools. Goldstein and Shapiro warn that school systems struggling to address the financial and logistical challenges of safe reopening must carefully investigate and address teacher concerns [13].

To date, a large number of studies have been conducted on the emotional consequences of the pandemic and its impact on the mental health of workers and the general population [15-21], whereas significantly fewer studies have been conducted with regard to the teacher population [22]. However, there is scientific evidence to suggest that mental strain is significant in the teacher population [23].

For elementary and secondary school teachers working in the distance education system implemented during the pandemic, it might also be supposed that musculoskeletal system and psychosocial problems may be experienced, as seen in studies conducted with people working at computers for a long time [24].

According to previous data from the literature, the factors related to psychological burdens, concern and anxiety are not fully known. Some studies have indicated that women, people of poorer socioeconomic status, from rural areas, as well as those at higher risk for COVID-19, have a higher prevalence of anxiety, but these results are not consistent in the literature [20].

Bearing in mind that the study of mental health during the pandemic is of great importance for other activities and vulnerable categories [25, 26], and given the role of teachers in society, the aim of this research is to assess teachers' concerns about reopening schools and their anxiety before the start of the 
school year, as well as to examine the factors related to teachers' concerns and anxieties about reopening schools and to propose measures in line with the results.

\section{Methods}

The study was conducted in August 2020 as a cross-sectional study before the start of the 2020/ 2021 school year. According to the Law on Primary Education and Upbringing and the Law on Secondary Education and Upbringing in the Republic of Srpska, before the beginning of the school year, all teachers are obliged to report for a preventive medical examination to the occupational medicine services. The research was conducted in the Institute for Occupational and Sports Medicine of the Republic of Srpska (Banja Luka) and the regional centres during preventive examinations. The consent of the director of the Institute for Occupational and Sports Medicine of the Republic of Srpska was obtained for conducting the research.

\subsection{Study population and sample}

The aim of the research was explained to the teachers, and the research was conducted anonymously and voluntarily, and the teachers who participated in the research signed the informed consent for participation.

According to the latest data from the Institute of Statistics of the Republic of Srpska, the total number of teachers in the Republic of Srpska is 12078, of which 8334 (69\%) are female, and 5994 (49.63\%) are under the age of $40.8134(67.35 \%)$ are employed in primary schools, of which $5848(71.90 \%)$ are female. The total number of teachers in primary schools under the age of 40 is $4182(51.41 \%) .3944$ (32.65\%) teachers are employed in secondary schools, of which 2486 $(63.03 \%)$ are female. The total number of teachers under the age of 40 in secondary schools is 1821 $(46.17 \%)$. Classroom teaching is held by primary school teachers in lower grades I-V and the total number of teachers in these grades is 3247 (26.88\%), of which $2850(87.77 \%)$ are female. All teachers in secondary schools have subject teaching classes $[27$, 28].

Due to the COVID-19 pandemic, the decision of the relevant Ministry extended the period of preventive examinations for teachers, so instead of reporting for examinations in September, teachers had a period until the end of December 2020 to do this. Therefore, in the period in which this research was conducted, a smaller number of teachers applied for a preventive examination, and a total of 400 questionnaires were distributed, of which 286 (71.5\%) were filled out in their entirety.

\subsection{Material}

For the purposes of this research, a special questionnaire was constructed consisting of a general questionnaire and a standardized scale for self-assessment of the degree of anxiety - General Anxiety Disorder (GAD-7; Supplementary Materials). The general questionnaire consisted of standard sociodemographic data (gender, age, place of residence, type of teaching), data on the household, personal health and health status of family members. Also, the questionnaire contained questions related to the data on COVID-19, i.e., whether they or any of their family members were in contact with the infected or were infected, whether they followed the recommendations for control of the infection issued by the authorities, whether they followed the information, whether they were satisfied with the available information on COVID-19, and whether they had any concerns for their life and health and the life and health of their family members because of the pandemic. As a special variable, teachers' concern about the reopening of schools was examined. One of the questions referred to their opinion on how classes should take place in the upcoming school year in pandemic conditions. With the permission of the author, we used a GAD-7 scale that had already been translated into Serbian and validated. Exploratory and confirmatory factor analyses have confirmed the exceptional psychometric properties of the GAD 7item scale [29]. The GAD-7 scale consists of seven theses expressing personal views in the last two weeks, and the answers are presented in the form of a four-point Likert scale. A score of 5 or higher indicates the presence of anxiety and is graded as mild [5-9], moderate [10-14], and severe anxiety (15 and higher) [30].

\subsection{Statistical data analysis}

Data were analyzed using the IBM SPSS Statistics 25 software, and statistical significance was shown for $p<0.05$. The methods of descriptive and inferential statistics were used in the article. From the methods of descriptive statistics, we used measures of 
central tendency (arithmetic mean and median), measures of variability (standard deviation) and relative numbers. The Pearson Chi-square test or Fisher's test was used to assess the difference between categorical variables. Logistic regression was used in the paper to estimate the predictive value of the dichotomous categorical variable of concerns about reopening schools.

\section{Results}

286 teachers participated in the research, of which the larger faction consisted of female teachers $(71 \%)$. More than half of the teachers were aged $31-50$ $(65.1 \%)$. Male teachers were more often over 40 years of age $(68.7 \%)$ and this is a statistically significant difference $(p<0.05)$. Subject teachers $(60.1 \%)$ mainly participated in the research. Female teachers more often performed the class type of teaching $(p<0.05)$. Socio-demographic characteristics of teachers are shown in Table 1.

A higher percentage of teachers stated that they were healthy $(89.2 \%)$ as well as their family members $(88.5 \%)$. Also, a higher percentage of teachers did not have COVID-19 until the research period (95.1\%). The largest number of teachers complied with all measures and recommendations for the prevention and control of COVID-19 (95.2\%) and followed the information on COVID-19 (94.1\%). In most cases, teachers were dissatisfied with the measures taken by the authorities to prevent and control COVID-19
(93\%). Compared to the available information on COVID-19, a higher percentage of teachers reported that they were dissatisfied with the available data on COVID-19 (90.9\%). A higher percentage of teachers were concerned for their life and health and for the life and health of their family members due to the COVID-19 pandemic (76.9\%). Female teachers were more often concerned $(84.7 \%)$ and this is a statistically significant difference $(p<0.001)$. More than half of the teachers expressed concern about reopening schools $(76.9 \%)$. Female teachers were more often concerned about reopening schools compared to male teachers ( $80.8 \%$ compared to $59 \%)$ and this is a statistically significant difference $(p<0.001)$. However, the largest percentage of teachers believe that the school year should be organized in the form of regular classes $(81 \%)$. However, a statistically significant difference was found in relation to gender $(p<0.05)$. Male teachers compared to female teachers more often thought that classes should be organized online (7.2\% compared to $3 \%$ ) or combined (20.5\% compared to $12.3 \%)$. Table 2 shows data on the health status of respondents and family members, satisfaction and compliance with preventive measures, available information, and satisfaction with information about COVID-19.

Table 3 shows data on the respondents' concern for their life and health and the life and health of their family members, and it also shows the respondents' concerns about reopening schools in the time of the pandemic.

Table 1

Socio-demographic characteristics of teachers

\begin{tabular}{|c|c|c|c|c|c|c|c|}
\hline \multirow{2}{*}{$\begin{array}{l}\text { Socio-demographic } \\
\text { characteristics }\end{array}$} & \multirow[b]{2}{*}{ All } & \multicolumn{3}{|c|}{ Sex } & \multicolumn{3}{|c|}{ Type of teaching } \\
\hline & & Male & Female & & $\begin{array}{c}\text { Classroom } \\
\text { teaching }\end{array}$ & $\begin{array}{c}\text { Subject } \\
\text { teaching }\end{array}$ & \\
\hline & $N(\%)$ & $N(\%)$ & $N(\%)$ & $p$ & $N(\%)$ & $N(\%)$ & $p$ \\
\hline \multicolumn{8}{|l|}{ Sex } \\
\hline Male & $83(29)$ & I & l & & $22(19.3)$ & $61(35.3)$ & .003 \\
\hline Female & $203(71)$ & l & l & & $92(80.7)$ & $111(64.5)$ & \\
\hline \multicolumn{8}{|l|}{ Age (years) } \\
\hline$<30$ & $19(6.6)$ & $3(3.6)$ & $16(7.9)$ & 0.040 & $5(4.4)$ & $14(8.1)$ & 0.266 \\
\hline $31-40$ & $92(32.2)$ & $23(27.7)$ & $69(34)$ & & $33(28.9)$ & $34.3)$ & \\
\hline $41-50$ & $94(32.9)$ & $24(28.9)$ & $70(34.5)$ & & $44(46.1)$ & 29.1) & \\
\hline$>51$ & $81(28.3)$ & $33(39.8)$ & $48(23.6)$ & & $32(28.1)$ & $49(28.5)$ & \\
\hline \multicolumn{8}{|l|}{ Residence } \\
\hline Rural & $120(42.0)$ & $28(33.7)$ & $92(45.3)$ & 0.086 & $49(43.0)$ & $71(41.3)$ & 0.807 \\
\hline Urban & $166(58.0)$ & $55(66.3)$ & $111(54.7)$ & & $65(57.0)$ & $101(58.7)$ & \\
\hline \multicolumn{8}{|l|}{ Household } \\
\hline Alone & $21(7.3)$ & $8(9.6)$ & $13(6.4)$ & 0.330 & $6(5.3)$ & $15(8.7)$ & 0.356 \\
\hline With family & $265(92.7)$ & $75(90.4)$ & $190(93.6)$ & & $108(94.7)$ & $157(91.3)$ & \\
\hline \multicolumn{8}{|l|}{ Type of teaching } \\
\hline Classroom teaching & $114(39.9)$ & $22(26.5)$ & $92(45,3)$ & 0.003 & / & l & \\
\hline Subject teaching & $172(60,1)$ & $61(73.5)$ & $111(54.7)$ & & / & l & \\
\hline
\end{tabular}


Table 2

Health status, preventive measures and information on COVID-19

\begin{tabular}{|c|c|c|c|c|c|c|c|}
\hline \multirow{2}{*}{$\begin{array}{l}\text { Health condition, preventive } \\
\text { measures and information about COVID-19 }\end{array}$} & \multirow[b]{2}{*}{$\begin{array}{c}\text { All } \\
N(\%)\end{array}$} & \multicolumn{3}{|c|}{ Sex } & \multicolumn{3}{|c|}{ Type of teaching } \\
\hline & & $\begin{array}{l}\text { Male } \\
N(\%)\end{array}$ & $\begin{array}{l}\text { Female } \\
N(\%)\end{array}$ & $p$ & $\begin{array}{c}\text { Classroom } \\
\text { teaching } \\
N(\%)\end{array}$ & $\begin{array}{c}\text { Subject } \\
\text { teaching } \\
N(\%)\end{array}$ & $p$ \\
\hline \multicolumn{8}{|l|}{ Personal health } \\
\hline Healthy & $255(89.2)$ & $72(86.7)$ & $183(90.1)$ & 0.346 & $105(92.1)$ & $150(87.7)$ & 0.325 \\
\hline Existence of disease & $25(8.8)$ & $9(10.8)$ & $16(7.9)$ & & $9(7.9)$ & $21(12.3)$ & \\
\hline \multicolumn{8}{|l|}{ The health of the family } \\
\hline Healthy & $253(88.5)$ & $75(90.4)$ & $178(87.7)$ & 0.520 & $103(90.4)$ & $150(87.2)$ & 0.455 \\
\hline Existence of disease & $33(11.5)$ & $8(9.6)$ & $25(12.3)$ & & $11(9.6)$ & $22(12.8)$ & \\
\hline \multicolumn{8}{|l|}{ Contact with the COVID-19 } \\
\hline No & $270(94.4)$ & $79(95.2)$ & $191(94.1)$ & 0.482 & $107(93.9)$ & $163(94.8)$ & 0.468 \\
\hline Yes & $16(5.6)$ & $4(4.8)$ & $12(5.9)$ & & $7(6.1)$ & $9(5.2)$ & \\
\hline \multicolumn{8}{|l|}{ Earlier COVID-19 status } \\
\hline Negative & $272(95.1)$ & $81(97.6)$ & $191(94.1)$ & 0.224 & $109(95.6)$ & $166(96.5)$ & 0.759 \\
\hline Positive & $12(4.2)$ & $1(1.2)$ & $11(5.4)$ & & $5(1.7)$ & $6(3.5)$ & \\
\hline \multicolumn{8}{|l|}{ Compliance with measures } \\
\hline No & $7(2.4)$ & $4(4.8)$ & $3(1.5)$ & 0.111 & $2(1.8)$ & $5(1.7)$ & 0.706 \\
\hline Yes & $279(95.2)$ & $79(95.2)$ & $200(98.5)$ & & $112(98.2)$ & $167(97.1)$ & \\
\hline \multicolumn{8}{|l|}{$\begin{array}{l}\text { Satisfaction with preventive } \\
\text { measures by the authorities }\end{array}$} \\
\hline Dissatisfied & $266(93.0)$ & $74(89.2)$ & $192(94.6)$ & 0.087 & $108(94.7)$ & $158(91.9)$ & 0.246 \\
\hline Satisfied & $20(7.0)$ & $9(10.8)$ & $11(5.4)$ & & $6(5.3)$ & $14(8.1)$ & \\
\hline \multicolumn{8}{|l|}{ Informed about COVID-19 } \\
\hline No & $17(5.9)$ & $8(9.6)$ & $9(4.4)$ & 0.082 & $4(3.5)$ & $13(7.6)$ & 0.121 \\
\hline Yes & $269(94.1)$ & $75(90.4)$ & $194(95.6)$ & & $110(96.5)$ & $159(92.4)$ & \\
\hline \multicolumn{8}{|l|}{$\begin{array}{l}\text { Satisfaction with information } \\
\text { about COVID-19 }\end{array}$} \\
\hline Dissatisfied & $260(90.9)$ & $71(85.5)$ & $189(93.1)$ & 0.040 & $108(94.7)$ & $152(88.4)$ & 0.049 \\
\hline Satisfied & $26(9.1)$ & $12(14.5)$ & $14(4.9)$ & & $6(5.3)$ & $20(7.0)$ & \\
\hline \multicolumn{8}{|l|}{ Way of teaching } \\
\hline Online & $12(4.2)$ & $6(7.2)$ & $6(3.0)$ & 0.042 & $5(4.4)$ & $7(4.1)$ & 0.645 \\
\hline Face-to-face & $232(81.1)$ & $60(72.3)$ & $172(84.7)$ & & $95(83.3)$ & $9.7)$ & \\
\hline Combined & $42(14.7)$ & $17(20.5)$ & $25(12.3)$ & & $14(12.3)$ & $28(16.3)$ & \\
\hline
\end{tabular}

Table 3

Teacher concerns

\begin{tabular}{|c|c|c|c|c|c|c|c|}
\hline \multirow[t]{2}{*}{ Teacher concerns } & \multirow[b]{2}{*}{$\begin{array}{c}\text { All } \\
N(\%)\end{array}$} & \multicolumn{3}{|c|}{ Sex } & \multicolumn{3}{|c|}{ Type of teaching } \\
\hline & & $\begin{array}{l}\text { Male } \\
N(\%)\end{array}$ & $\begin{array}{l}\text { Female } \\
N(\%)\end{array}$ & $p$ & $\begin{array}{c}\text { Classroom } \\
\text { teaching } \\
N(\%)\end{array}$ & $\begin{array}{c}\text { Subject } \\
\text { teaching } \\
N(\%)\end{array}$ & $p$ \\
\hline \multicolumn{8}{|c|}{$\begin{array}{l}\text { Concerns for life and health of } \\
\text { themselves and family members }\end{array}$} \\
\hline No & $66(23.1)$ & $35(42.2)$ & $31(15.3)$ & 0.000 & $25(21.9)$ & $41(23.8)$ & 0.410 \\
\hline Yes & $220(76.9)$ & $48(57.8)$ & $172(84.7)$ & & $89(78.1)$ & $131(76.2)$ & \\
\hline \multicolumn{8}{|c|}{ Concerns for reopening schools } \\
\hline No & $73(25.5)$ & $34(41.0)$ & $39(19.2)$ & 0.000 & $28(24.6)$ & $45(26.2)$ & 0.436 \\
\hline Yes & $213(74.5)$ & $49(59.0)$ & $164(80.8)$ & & $86(75.4)$ & $127(3.8)$ & \\
\hline
\end{tabular}

On the GAD-7 scale, the arithmetic mean of the examined population is 0.64 (SD 1.22, rank 0-9), which indicates a normal degree of anxiety in the examined population. Only $2 \%$ of teachers had mild anxiety. Moderate and severe anxiety was not reported. Table 4 shows anxiety in the study population.
Binary logistic regression was conducted to assess the impact of multiple factors on the likelihood that respondents would say that they were concerned about reopening schools during the pandemic. Following previous research, the initial variables obtained from the empirical and theoretical approach 
Table 4

Anxiety

\begin{tabular}{|c|c|c|c|c|c|c|c|}
\hline \multirow[t]{2}{*}{ Anxiety } & \multirow[b]{2}{*}{$\begin{array}{c}\text { All } \\
N(\%)\end{array}$} & \multicolumn{3}{|c|}{ Sex } & \multicolumn{3}{|c|}{ Type of teaching } \\
\hline & & Male & $\begin{array}{l}\text { Female } \\
N(\%)\end{array}$ & $p$ & $\begin{array}{c}\text { Classroom } \\
\text { teaching } \\
N(\%)\end{array}$ & $\begin{array}{c}\text { Subject } \\
\text { teaching } \\
N(\%)\end{array}$ & $p$ \\
\hline No & $280(97.9)$ & $82(98.8)$ & $198(97.5)$ & 0.440 & $112(98.2)$ & 168 (97.7) & 0.547 \\
\hline Low & $6(2.1)$ & $1(1.2)$ & $5(2.5)$ & & $2(1.8)$ & $4(2.3)$ & \\
\hline Moderate & 0 & 0 & 0 & & 0 & 0 & \\
\hline High & 0 & 0 & 0 & & 0 & 0 & \\
\hline
\end{tabular}

Table 5

Variables

\begin{tabular}{|c|c|c|c|}
\hline $\begin{array}{l}\text { Variable } \\
\text { (个-increases } \\
\text { probability) }\end{array}$ & $\begin{array}{l}\text { Variable selection } \\
\text { Theoretical approach } \\
\text { (T) Empirical } \\
\text { approach (E) }\end{array}$ & Tolerance & VIF \\
\hline Sex (female) & $\mathrm{T}$ & 0.866 & 1.55 \\
\hline Age (50 and above) & $\mathrm{T}$ & 0.903 & 1.107 \\
\hline Residence (urban) & $\mathrm{E}$ & 0.964 & 1.037 \\
\hline Household (with family) & $\mathrm{E}$ & 0.914 & 1.094 \\
\hline Type of teaching (subject teaching) & $\mathrm{E}$ & 0.937 & 1.067 \\
\hline Personal health (existence of disease) & $\mathrm{T}, \mathrm{E}$ & 0.936 & 1.068 \\
\hline The health of the family (existence of disease) & $\mathrm{T}, \mathrm{E}$ & 0.871 & 1.148 \\
\hline $\begin{array}{l}\text { Contact with the COVID-19 } \\
\text { positive (close contact) }\end{array}$ & $\mathrm{E}$ & 0.687 & 1.455 \\
\hline Earlier COVID-19 status (negative) & $\mathrm{T}, \mathrm{E}$ & 0.678 & 1.474 \\
\hline Compliance with measures (yes) & $\mathrm{E}$ & 0.681 & 1.469 \\
\hline $\begin{array}{l}\text { Satisfaction with preventive measures } \\
\text { by the authorities (dissatisfied) } \\
\text { Informed about COVID-19 }\end{array}$ & $\mathrm{E}$ & 0.681 & 1.468 \\
\hline $\begin{array}{l}\text { Satisfaction with information } \\
\text { about COVID-19 (dissatisfied) }\end{array}$ & E & 0.648 & 1.543 \\
\hline $\begin{array}{l}\text { Concerns for life and health of themselves } \\
\text { and family members } \\
\text { (the existence of concerns) }\end{array}$ & E & 0.755 & 1.325 \\
\hline
\end{tabular}

in the previous part of this article were selected for the model. All selected variables are of the dichotomous type, with the exception of the variable 'age'.and are shown in Table 5. Before being included into the model for the purpose of a more adequate interpretation of results, the variable 'age' was turned into a dichotomous variable (under the age of $50=0$, over the age of $50=1$ ).

The model contained 14 variables. Before the start of the data analysis, the correctness of the data was checked and it was determined that no data disturbed the correctness of the final result. It was also determined that there was no multicollinearity, or in other words, there were no strong intercorrelations of predictor variables. Given the fact that, in formal terms, the procedure of SPSS logistic regression did not have a collinearity test, we used collinearity diagnostics from the linear regression.

The values of the Tolerance indicator ranged from 0.65 to 0.96 , and the VIF from 1.03 to 1.47 , which indicates that the variables do not have high correlations with other variables in the model. The results of the first step of logistic regression are shown in Table 6.

The whole model with all predictors was statistically significant c2 $(13, N=286)=97.94, p<0.001$, which shows that the model distinguishes between respondents who did and those who did not answer that they were concerned about reopening schools. Based on the Cox and Snell R Square (,290) and Nagelkerke R Square $(, 472)$ we calculated that the model with all predictors explains between $29.0 \%$ and $42.7 \%$ of the variance and accurately classifies $83.6 \%$ of cases. The Omnibus test showed that the tested model of prediction variables gives a good explanation of the outcome variable ( $\mathrm{Sig}=0.000, \mathrm{H}^{2}=92,15$, df- 3 ). In addition, the Hosmer-Lemeshow test enabled us to establish the significance of the model (Sig. $=0.921, \mathrm{H}^{2}=0.492$, df-3). 
Table 6

Logistic regression step 1: impact of multiple factors on the likelihood that respondents would respond to concern about reopening school in a pandemic

\begin{tabular}{|c|c|c|c|c|c|c|c|c|}
\hline \multirow[t]{2}{*}{ Variables } & \multirow[t]{2}{*}{ B } & \multirow[t]{2}{*}{ S.E. } & \multirow[t]{2}{*}{ Wald } & \multirow[t]{2}{*}{ df } & \multirow[t]{2}{*}{ Sig. } & \multirow[t]{2}{*}{$\operatorname{EXP}(B)$} & \multicolumn{2}{|c|}{ 95\% C.I.for } \\
\hline & & & & & & & Lower & Upper \\
\hline Sex (female) & 0.680 & 0.386 & 3.101 & 1 & 0.078 & 1.974 & 0.926 & 4.206 \\
\hline Age (50 and above) & 1.236 & 0.621 & 3.953 & 1 & 0.047 & 3.440 & 1.018 & 11.628 \\
\hline Residence (urban) & 0.314 & 0.353 & 0.788 & 1 & 0.375 & 1.369 & 0.685 & 2.736 \\
\hline Type of teaching (subject teaching) & 0.255 & 0.362 & 0.494 & 1 & 0.482 & 1.290 & 0.634 & 2.624 \\
\hline Household (with family) & 0.693 & 0.621 & 1.245 & 1 & 0.264 & 2.000 & 0.592 & 6.756 \\
\hline Personal health (existence of disease) & 0.073 & 0.601 & 0.015 & 1 & 0.903 & 1.076 & 0.331 & 3.497 \\
\hline $\begin{array}{l}\text { The health of the family } \\
\text { (existence of disease) }\end{array}$ & -0.464 & 0.565 & 0.675 & 1 & 0.411 & 0.629 & 0.208 & 1.902 \\
\hline $\begin{array}{l}\text { Contact with with the COVID-19 } \\
\text { positive (close contact) }\end{array}$ & 0.702 & 0.950 & 0.545 & 1 & 0.460 & 2.017 & 0.313 & 12.982 \\
\hline Earlier COVID-19 status (negative) & -0.556 & 0.892 & 0.389 & 1 & 0.533 & 0.573 & 0.100 & 3.295 \\
\hline Compliance with measures (yes) & 1.733 & 1.484 & 1.363 & 1 & 0.243 & 5.659 & 0.309 & 103.788 \\
\hline $\begin{array}{l}\text { Satisfaction with preventive measures } \\
\text { by the authorities (dissatisfied) }\end{array}$ & -0.264 & 0.709 & 0.139 & 1 & 0.709 & 0.768 & 0.191 & 3.081 \\
\hline Infotmation about COVID-19 (yes) & 2.253 & 0.846 & 7.092 & 1 & 0.008 & 9.519 & 1.813 & 49.982 \\
\hline $\begin{array}{l}\text { Satisfaction with information } \\
\text { about COVID-19 (dissatisfied) }\end{array}$ & -0.533 & 0.636 & 0.702 & 1 & 0.402 & 0.587 & 0.169 & 2.040 \\
\hline $\begin{array}{l}\text { Concerns for life and health of } \\
\text { themselves and family members } \\
\text { (the existence of concerns) }\end{array}$ & 2.413 & 0.390 & 38.202 & 1 & 0.000 & 11.170 & 5.197 & 24.011 \\
\hline
\end{tabular}

Table 7

Logistic regression step 11: Impact of multiple factors on the likelihood that respondents would respond to concern about reopening school in a pandemic

\begin{tabular}{|c|c|c|c|c|c|c|c|c|}
\hline \multirow[t]{2}{*}{ Variables } & \multirow[t]{2}{*}{ B } & \multirow[t]{2}{*}{ S.E. } & \multirow[t]{2}{*}{ Wald } & \multirow[t]{2}{*}{ df } & \multirow[t]{2}{*}{ Sig. } & \multirow[t]{2}{*}{$\mathrm{EXP}(\mathrm{B})$} & \multicolumn{2}{|c|}{ 95\% C.I.for } \\
\hline & & & & & & & Lower & Upper \\
\hline Age (50 and above) & 1.203 & 0.564 & 4.553 & 1 & 0.033 & 3.330 & 1.103 & 10.055 \\
\hline $\begin{array}{l}\text { Concerns for life and health } \\
\text { of themselves and family members } \\
\text { (the existence of concerns) }\end{array}$ & 2.601 & 0.351 & 55.040 & 1 & 0.000 & 13.480 & 6.780 & 26.800 \\
\hline Informed about COVID-19 & 2.315 & 0.746 & 9.621 & 1 & 0.002 & 10.121 & 2.344 & 43.695 \\
\hline
\end{tabular}

Only three variables made a unique statistically significant contribution to the model (age of respondents, concerns for their life and health and the life and health of their family members, and available information on COVID-19). We further applied the stepwise analysis backward, i.e., we gradually removed the independent variables from the model. Removal was performed in 11 steps. In each step, one variable with the lowest contribution to the model was removed. Removal proceeded in the following order: personal health (sig. 903), satisfaction with preventive measures (sig. 713), previous COVID-19 status (sig. 564), contact with COVID-19 positive persons (sig. 616), workplace (sig. 490), satisfaction with information about COVID-19 sig. 540), family health (sig. 411), residence (sig. 335), compliance with measures (sig. 277), household (sig. 242), sex (sig. 104).

The final model with three predictors was statistically significant $\mathrm{c} 2(3, N=286)=89.53, p<0.001$. Based on the Cox and Snell R Square $(, 269)$ and
Nagelkerke R Square (,396), we calculated that the model as a whole explains between $26.9 \%$ and $39.6 \%$ of the variance and accurately classifies $83.2 \%$ of the cases. The final model with three predictors, which was checked with the Omnibus test, was statistically significant $(\mathrm{Sig} .=0.000, \mathrm{H} 2=89.53, \mathrm{df}-3)$, and it was also checked with the Hosmer-Lemeshow test $\left(\mathrm{Sig} .=0.661, \mathrm{H}^{2}=0.829, \mathrm{df}-2\right)$. The strongest predictor of a teacher's answer that they were concerned about the reopening of schools was their concern for their own life and health and for the life and health of their family members, followed by the amount of information received about COVID-19, and, finally, older age (50 and above).

\section{Discussion}

This is the first study in the Republic of Srpska to assess the mental health of teachers during a 
pandemic. The study was conducted as a crosssectional study in August before the start of the school year 2020/2021. Having in mind the COVID19 pandemic, due to which the working conditions of teachers have changed, and bearing in mind that, during their work, teachers are inevitably exposed to contact with a large number of people, from children to colleagues and even parents, thus being at a higher risk of infection, it was assumed that they would be worried about the beginning of the new school year, that is, that they would show a higher degree of anxiety. Therefore, a survey was conducted before the beginning of the school year to assess the concerns and anxiety of teachers, as well as to suggest further measures to preserve and improve the mental health of this vulnerable population.

Female teachers participated in the research more often $(71 \%)$ (Table 1$)$, which corresponds to the population count of teachers in the Republic of Srpska (Institute of Statistics of the Republic of Srpska, 2020a, 2020b). A slight difference was observed in relation to the age and type of teaching of teachers in the sample and in the teacher population in the Republic of Srpska. Teachers over the age of 40 participated more often in the survey (56.7\%) (Table 1), while according to the Institute of Statistics of the Republic of Srpska, the percentage of teachers over the age of 40 is $49.63 \%$ (Institute of Statistics of the Republic of Srpska, 2020a, 2020b). 60\% of subject teachers participated in the research (Table 1), and in the population of subject teachers in the Republic of Srpska they had a slightly higher percentage (73.12\%) (Institute of Statistics of the Republic of Srpska, 2020a, 2020b). The reasons why a higher percentage of older teachers accepted the invitation to participate in the research are unknown. The results of this research indicate that teachers older than 40 were more likely to report that they were concerned about their life and health and the life and health of their family members (61.2\%), and the same percentage of teachers showed concern about reopening schools. It is possible that a higher percentage of them underwent the preventive examination precisely because they were concerned for their own life and health.

A substantial number of teachers reported that they were concerned about reopening schools during the pandemic $(74.5 \%)$, with female teachers reporting concern more often $(80.8 \%)$, which is a statistically significant difference $(p<0.001)$ (Table 3). A statistically significant difference was not found in the concerns of teachers relating to the type of teaching they were engaged in (Table 3 ). We did not find data from other countries to compare these results with, while studies in the general population showed a moderate degree of concerns in the studied populations, and they also showed that women are more prone to concerns, their concerns being mainly related to the possibility of getting infected, their loved ones dying, becoming isolated, or being discriminated against (31-33). Female teachers were statistically significantly more dissatisfied with the information (Table 2) from the media about COVID19 , which may be the result of differences in concerns between the sexes, or simply because females are more prone to emotional reactions. Similar results revealing that females are more prone to anxiety as well as stress and other mental disorders can be found in other items of literature [20,34,35], and therefore, in the following period, it follows naturally that special attention should be paid to the mental health of this sensitive group.

Bearing in mind that a significant number of teachers reported that they were concerned about their life and health and the life and health of their families (76.9\%) (Table 3), we assume that the reported concern about reopening schools is the result of concerns about the possibility of getting infected and their loved ones dying. However, despite that, a higher percentage of teachers gave the information that they wanted classes to be held regularly (84.7\%) (Table 2). Similar results were obtained by the authors in a survey conducted in the population of teachers in high schools, where more than half of teachers expressed a desire to return to work [22]. Stachteas and Stachteas, for instance, provided such results, which is expected given that online teaching requires teachers to act beyond their traditional understandings of the teaching process, and further questioned the ability to use IT technology [7].

According to the results, $93 \%$ of teachers are dissatisfied with the measures taken by the authorities in order to combat the pandemic (Table 2), while the concerns for life and health proved to be a significant variable associated with concerns about reopening schools (Table 6). Research in the following period should be conducted on measures and available means of protection in schools; i.e., in accordance with the results, protection measures should be improved, which would inevitably reduce the level of teachers' concerns and their psychological burden.

Another variable in this study, which had a statistically significant contribution to the outcome variable of concerns about reopening schools, is also exposure 
to information from the media about COVID-19 (Table 6). The results of this research showed that the largest percentage of teachers followed the information on COVID-19 (94\%) (Table 2). They were generally dissatisfied with the available information (90.9\%), with female teachers $(93 \%)$ and primary school teachers $(94.7 \%)$ stating that they were more dissatisfied than male and subject teachers $(p<0.05)$ (Table 2). Regarding the type of teaching, this result is probably related to the percentage share of the female teacher population in the number of primary school teachers in the examined sample $(80.7 \%)$, since women teachers were significantly more dissatisfied (Table 2). According to these results, research on the impact of the media should be conducted in the future, and if these results are confirmed, it is necessary to take measures to reduce media exposure to COVID-19.

Teacher age ( $>50$ years) is a variable that also had a statistically significant contribution to the concerns about reopening schools (Table 6). This can be explained by the fact that mortality from COVID-19 is higher in the elderly population, although data from other studies have indicated that younger people are more worried. The authors explained this by possibly better emotional regulation and coping mechanisms in the elderly population [32].

Given that there is evidence that concerns are associated with consequences in the form of increased risk of cardiovascular disease, poorer physical health, decline in learning and memory [32], depressive symptoms [36] and other negative effects on mental health [35], and that a significant predictor of concern is the existence of dysfunctional coping mechanisms [31], and that the study indicated a significant prevalence of concerns in the teacher population, it follows naturally that additional research on concern-related factors in this population is needed. Results of this research indicate that teachers need more support in concern management. One of the interventions could be to provide online psychological support to teachers.

However, a study is worth mentioning which indicated that the concern is related to the protective tendency of citizens to respect preventive measures and thus protect themselves and the environment [33, 37], and therefore it is also necessary to examine in more detail the degree of concern in teachers and its impact on their functionality, life and work. That is, it is necessary to implement procedures that would regularly monitor the mental health of teachers, for a timely preventive response.
In the examined sample, teachers did not show anxiety; only $2 \%$ of teachers had a mild degree of anxiety. We found one study conducted in China that examined anxiety in a large population of teachers and the prevalence of anxiety was about 13\% [38]. However, the results cannot be compared because, by the research period, China had already been significantly affected by the pandemic. The results of the research showed that mental disorders during the pandemic were related to the measures taken, loss of control, and the number of the infected and dead [39]. Bearing in mind that, by the research period, the spread of infection in the Republic of Srpska had been partially under control, one of the assumptions is that because of this, teachers showed a lower degree of anxiety. The results of this study are in line with this assumption: only $5.6 \%$ of teachers and their family members had contact with COVID-19 positive persons, and $4.2 \%$ were positive (Table 2). Also, the difference in mentality between the populations should be taken into account. However, it should be mentioned that the results of the study in the Republic of Srpska are contradictory to the results of the study in the general population. According to the data, the prevalence of anxiety associated with COVID-19 in the general population is $15 \%$, which is a significant difference compared to the general population under normal conditions $(3.6 \%)$ [39]. The results of the second meta-analysis showed that the prevalence of anxiety in the general population is as high as about $28-39 \%$ [20]. However, the results of this research should be taken with caution. It can be assumed that teachers who have impaired mental health refused to participate in the research because the response rate was $71.5 \%$. Also, having in mind that the period of preventive examinations was extended until December, it can be assumed that anxious teachers did not report immediately for the examination, avoiding contact with the health service, and that they were therefore not included in this research. Also, it should be emphasized that teachers are university-educated people and that they are therefore capable of recognizing socially "desirable" answers, which is why it can be assumed that the tendency to write socially desirable answers could also influence the result of anxiety self-assessment. Teachers who are healthy (89.2\%) and whose family members are healthy (88.5\%) participated in the research, and it can be assumed that this could have had an impact on the research results, given that they are not a vulnerable category for COVID-19. It is possible that teachers who are ill or whose 
family members are ill did not participate in this research, because they prolonged their attendance at the periodic examination. Also, a higher percentage of teachers before the research did not have contact with a patient or someone tested positive for COVID19 (94.4\%) and were not ill. Due to the low prevalence of anxiety in the examined sample, we did not conduct statistical tests to examine the correlation of the examined variables with anxiety. Bearing in mind that the peak of the epidemic in the Republic of Srpska was during the autumn months, when there was a sudden interruption in online learning, which resulted in protests by teachers and parents, there is a need to repeat this research as soon as possible and compare the results.

\section{Limitations}

The results of this study should be interpreted following the methodological limitations of the study. One of the limitations of this research is the design of the study - a cross-sectional study that prevents the formation of a cause-and-effect relationship. Therefore, future research should be longitudinal. Also, a weakness of this research is the number of teachers who participated in the research, that is, $2.37 \%$ of the teacher population. A significant limitation of this research is the use of self-reported measures, and more objective measures should be used in future studies to minimize bias. Also, the initial variable of concern about reopening schools was measured using only one question, so in the next research a standardized scale should be used.

Despite these limitations, given that the number of studies in the teacher population has been limited so far, the results of this study offer some input to researchers in understanding the psychological and mental health status of teachers at the time of the pandemic. This research primarily indicated the high prevalence of concern due to work in pandemic conditions, and following the results of other research, it suggested the importance of timely and regular monitoring of the mental health status of this population. It partially indicated factors associated with a high prevalence of concern, such as exposure to media information, and the results could be used in planning further research and interventions. Also, one of the strengths of this research is an adequate response rate, over $70 \%$, as well as the use of a standardized and validated companion to assess the degree of anxiety.

\section{Conclusion}

Having in mind the high prevalence $(74.5 \%)$ of teacher concern about reopening schools, this research indicated that in the following period it would be necessary to examine in more detail the degree of teachers' concern and its impact on their functionality and work process. It is also necessary to repeat the study on the mental health status of teachers and possibly, due to the results of other studies, to repeat the study on the impact of the pandemic on mental health in order to be able to implement procedures in the form of a regular screening program of teachers' mental health, for a timely preventive response. Screening could be carried out by the psychological and social services of schools, which would regularly monitor the mental health of teachers, for example, at least at the beginning and at the end of each semester over the course of the epidemic, or it would be possible to introduce anonymous online psychological support, which would be available all the time.

In accordance with the results stating that $93 \%$ of teachers are dissatisfied with the measures taken by the authorities in order to combat the pandemic, and given the fact that teachers' concern for their life and health and for the life and health of their family members has proven to be a significant variable related to concerns about reopening schools, a survey on measures and available means of protection in schools is needed, and once the survey results are obtained, it is necessary to increase the safety and satisfaction of teachers, which would reduce their psychological burden.

\section{Acknowledgments}

This work was supported by the grant "IMP002 Research on educational activities and educational work in the conditions of the COVID-19 pandemic - online teaching, distance teaching, hybrid teaching. Analysis of digital competencies of educators and digital maturity of schools", which is generously supported and financed by the Teacher Training Faculty in Prizren - Leposavic, University of Pristina Kosovska Mitrovica.

\section{Conflict of interest}

No potential conflict of interest was reported by the authors. 


\section{Supplementary data}

The questionnaire is available from https:// dx.doi.org/10.3233/WOR-210885.

\section{References}

[1] Ali S, Alam BF, Noreen S, Anwar M, Qazi SH, Hussain T. Motivation and job satisfaction among medical and dental college faculty in Pakistan amid the COVID-19 outbreak. Work. 2021;69(2):359-66.

[2] Ivanović V. Pojam krize : konceptualni i metodologijski aspekti Uvod. Me*dunarodne studije. 2014;14(2):10-28.

[3] Hodges C, Moore S, Lockee B, Trust T, Bond A. The difference between emergency remote teaching and online learning. Educause Review. 2020.

[4] David R, Pellini A, Jordan K, Phillips T. Education during the COVID-19 crisis. Opportunities and constraints of using EdTech in low-income countries. The EdTech hUB. 2020.

[5] Eder R. The Remoteness of Remote Learning : A Policy Lesson from COVID19. OJED. 2020;9(1):168-71.

[6] Simeunović V. Organizing the system education in social crises. Pedagogical Reality. 2004;5(6):409-20.

[7] Mohmmed AO, Khidhir BA, Nazeer A, Vijayan VJ. Emergency remote teaching during Coronavirus pandemic : the current trend and future directive at Middle East College Oman. Innovative Infrastructure Solutions. 2020;5(72).

[8] Kamenetz A, Isensee L. Most Teachers Concerned About In-Person School; 2 In 3 Want To Start The Year Online. 2020.

[9] Axelrod J. Teachers want to go back to school - if it's safe. But they worry it won't be. 2020.

[10] Carvalhais C, Querido M, Pereira CC, Santos J. Biological risk assessment: A challenge for occupational safety and health practitioners during the COVID-19 (SARS-CoV-2) pandemic. Work (Reading, Mass). 2021;69(1):3-13.

[11] Cohen R, Delacourt C, Guen CG, Launay E. COVID-19 and schools. Guidelines of the French Pediatric Society. Archives de Pediatrie. 2020;27(7):388-92.

[12] Levinson M, Cevik M, Lipsitch M, Phil D. Reopening Primary Schools during the Pandemic. N Engl J Med. 2020;383:981-5.

[13] Goldstein E, Lipsitch M, Cevik M. On the Effect of Age on the Transmission of SARS-CoV-2 in Households, Schools, and the Community. The Journal of Infectius Deseases. 2021;223:362-9.

[14] Grush L. Teacahers share their biggest fears about reopening schools during the pandemic. 2020.

[15] Arora T, Grey I, Östlundh L, Bong K, Lam H, Omar OM, et al. The prevalence of psychological consequences of COVID-19 : A systematic review and meta- analysis of observational studies. 2020.

[16] Serafini G, Parmigiani B, Amerio A, Aguglia A, Sher L, Amore M. The psychological impact of COVID-19 on the mental health in the general population. 2020;(June): 529-35.

[17] Ren X, Huang W, Pan H, Huang T, Wang X. Mental Health During the Covid-19 Outbreak in China : a Meta-Analysis. Psychiatric Quaererly. 2020.

[18] Salari N, Hosseinian-Far A, Jalali R, Vaisi-Raygani A, Rasoulpoor S, Mohammadi M, et al. Prevalence of stress, anxiety, depression among the general population during the COVID-19 pandemic: a systematic review and metaanalysis. Globalization and Health. 2020;;16(1):57.

[19] Pappa S, Ntella V, Giannakas T, Giannakoulis VG, Papoutsi E, Katsaounou P. Prevalence of depression, anziety, and insomnia among healthcare workers during the COVID-19 pandemic: A systematic review and meta-analysis. Brain, behavior, and Immunitz. 2020.

[20] Wang Y, Kala MP, Tazeen HJ. Factors associated with psychological distress during the coronavirus disease 2019 (COVID-19) pandemic on the predominantly general population: A systematic review and meta- analysis. PLoS ONE. 2020;15(12):e0244630.

[21] Kabasakal E, Özpulat F, Akca A, Özcebe LH. COVID 19 fear and compliance in preventive measures precautions in workers during the COVID - 19 pandemic. International Archives of Occupational and Environmental Health. 2021.

[22] Stachteas P, Stachteas C. The psychological impaactof the COVID-19 pandemic on secondary school teachers. Psychiatriki. 2020;31(4):293-301.

[23] Du J, Mayer G, Hummel S, Oetjen N, Gronewold N, Yafar A, et al. Mental Health Burden in Different Professions During the Final Stage of the COVID-19 Lockdown in China : Cross-sectional Survey Study. Journal of Medical Internet Research. 2020;22(12):e24240.

[24] Kayabinar E, Kayabinar B, Önal B, Zengin HY, Köse N. The musculoskeletal problems and psychosocial status of teachers giving online education during the COVID-19 pandemic and preventive telerehabilitation for musculoskeletal problems. Work. 2021;68(1):33-43.

[25] Depierro J, Lowe S, Katz C. Lessons learned from 9/11: Mental health perspectives on the COVID-19 pandemic. 2020;(January).

[26] Holmes EA, O Connor RC, Perry VH, Tracey I, Wessely $\mathrm{S}$, Arseneault L, et al. Multidisciplinary research priorities for the COVID-19 pandemic : a call for action for mental health science. Lancet Psychiatry. 2020;7:547-60.

[27] Institute of statistics Republic of Srpska. Statistical bulletin, Primary education 2019/2020. 2020.

[28] Institute of statistics Republic of Srpska. Statistical bulletin, Secondary Education 2019/2020. 2020.

[29] Rokvić N. The validation of the Serbian version of General Anxiety Disorder Scale (GAD7): A pilot study. PILOT STUDY. Engrami. 2019;41(2):69-79.

[30] Bäuerle A, Teufel M, Musche V, Weismüller B, Kohler H, Hetkamp M, et al. Increased generalized anxiety, depression and distress during the COVID-19 pandemic : a crosssectional study in Germany. Journal of Public Health. 2020; 1-7.

[31] Sebri V, Cincidda C, Ongaro G, Pravettoni G. Worry during the initial height of the COVID-19 crisis in an Italian sample. The Juornal of General Psychology. 2021.

[32] Barber SJ, Kim H. COVID-19 Worries and Behavior Changes in Older and Younger Men and Women. Journals of Gerontology: Psychological Sciences. 2020;20(20):1-7.

[33] States C-PU, Mcknight-eily LR, Okoro CA, Strine TW, Verlenden J, Hollis ND. Racial and Ethnic Disparities in the Prevalence of Stress and Worry, Mental Health Conditions, and Increased Substance Use Among Adults During the. Morbidity and Mortality Weekly Report. 2021;70(5):162-6.

[34] Lehmann S, Skogen JC, Haug E, Mæland S, Fadnes LT, Sandal GM, et al. Perceived consequences and worries among youth in Norway during the COVID-19 pandemic lockdown. Sandinavian Journal of Public Health. 2021;1-11.

[35] Yildirim M, Ozaslan A. Worry, Severity, Controllability, and Preventive Behaviours of COVID-19 and Their 
Associations with Mental Health of Turkish Healthcare Workers Working at a Pandemic Hospital. International Journal of Mental Health and Addiction. 2021.

[36] Karaivazoglou K, Konstantopoulou G, Kalogeropoulou M, Iliou T, Vorvolakos T, Assimakopoulos K, et al. Psychological distress in the Greek general population during the first COVID-19 lockdown. BJ Psych Open. 2021;7(e59):1-7.

[37] Kapoor H, Tagat A. Worry much ? Preventive health behaviours related to worry across countries amid COVID19. Journal of Health Psychology. 2021;00(0):1-12.
[38] Lia Q, Yudong M, Xin Z, Cliford Silver T, Cuiping W, Jian W. Prevalence and factors for anxiety during the coronavirus disease 2019 (COVID-19) epidemic among the teachers in China. Journal of Affective Disorders. 220AD;277:153-8.

[39] Cenat JM, Blais-Rochette C, Kokou-Kpolou CK, Noorishad P-G, Mukunzi NJ, McIntee SE, et al. Prevalence of symptoms of depression, anxiety, insomnia, posttraumatic stress disorder, and psychological distress among populations affected by the COVID-19 pandemic: A systematic review and meta-analysis. Psychiatry Research. 2020. 